\title{
MEDICAL INFORMATICS SPECIALTY \\ IN THE DEVELOPED ENGLISH-SPEAKING COUNTRIES: THE TERMINOLOGY COMPARATIVE ANALYSIS
}

\begin{abstract}
The article studies the development process of medical informatics specialty terminology as the ground for further research into foreign countries' experience, including the Canadian one, of specialists' professional training in the field of MI. The study determines the origin and chief stages of the formation and development of the medical informatics terminological system. The author performs the comparative analysis of terms used by the world organizations on health care informatisation issues, particularly International Medical Informatics Association as well as medical informatics associations of the USA and Canada as the leading countries where qualified workforce in the medical informatics specialty is trained. The European and Ukrainian experience has also been taken into consideration. The results of the comparative study have shown that the English terms 'medical informatics', 'biomedical informatics' and 'health informatics' serve as the umbrella terms for professional training programs and include a set of subspecialties that identify diverse spheres of information technology applications to medical science and practice, namely 'clinical informatics', 'bioinformatics', 'health care informatics', 'nursing informatics', 'imaging informatics', etc.

Key words: professional education, medical informatics specialty, professional training, practical skills, health informatics, biomedical informatics.

\section{INTRODUCTION}

In the middle of the 20th century, the penetration of information technologies into medicine and health care led to the appearance of a new applied science, academic discipline and later on a specialty that is presently termed medical informatics (MI). As the field is relatively young and develops quickly, there is no consistency in its definitions and nomenclature. One of the illustrative examples here is the existence of a set of terms in English scientific literature that are concerned with the notion of MI. The most common among them are medical informatics, bioinformatics, biomedical informatics, health informatics, clinical informatics, etc. The American scientist W. Hersh defines the phenomenon of diverse and unstandardised usage of determining adjectives in the MI terminology as "adjective problem", thus explaining ambiguities and confusion of terms in the nominative system of the field (Hersh, 2009).

So, today there is the obvious necessity for detailed analysis and concretization of the main notions that deal with computer technologies application to medicine, health care system informatisation and workforce professional training in the MI specialty.
\end{abstract}




\section{THE AIM OF THE STUDY}

The research is performed in order to analyze English terminological system denoting the MI field and to determine those terminological units that serve as umbrella terms for the specialty as well as those considered the names of the MI subspecialties.

\section{THEORETICAL FRAMEWORK AND RESEARCH METHODS}

The methodology of our research implies applying a number of theoretical research methods. We have used the comparative and historical method for studying the origin, formation and development of MI as a science and a specialty; the logical method for finding objective laws of the concept formation and reasoning in MI; induction and deduction for collecting theoretical and factual material with its generalization, analysis and synthesis for concretizing the subject matter of the main notions and terms; comparison and collation of the terminological system used by the leading world MI organizations that are engaged in studying the problems of health care system informatisation and specialists' professional training in the field of MI. In particular, we compared the terminology operated in the activities of International Medical Informatics Association IMIA, American Medical Informatics Association AMIA, Canada's Health Informatics Association COACH as well as European Federation of Medical Informatics EFMI and Ukrainian Association for "Computer Medicine".

\section{RESULTS}

The retrospective analysis of the MI terminological system development is of great importance in the context of studying specialists' professional training in the field of MI. The results of the conducted research have distinguished three main stages in formation and development of the specialty terminology.

The first stage is related to the generation of the notion of MI (the 1950s-1970s). The term 'medical informatics' appeared only in the 1970s although the emergence of the new science dates back to 1959 when the American scientists and radiologists R. Ledley and L. Lusted published the article in which the authors gave reasons for using computers to optimise statistical data processing in medical diagnostics. It was the first time when the terms 'medical computer science' and 'medical information science' were used in English scientific literature (Shortliffe, 2013). Later on, however, it became apparent that the terms proposed in 1959 did not fully convey the essence of the notion.

The second stage reflects the purposeful formation of the terminology in the MI field (the 1970s-1990s). In 1974 the book "Education in Informatics of Health Personal" was published. The collective authors led by the British researcher J. Anderson proposed the term 'medical informatics' as a basic one to denote the practice of computers application to medicine. Although the work did not provide a scientifically approved definition of the given term, it proposed the equivalent fully reflecting the content of the new scientific field. As the word 'informatics' has polyfunctional nature and gives the name to the science dealing with information processing, its proper storage and effective usage, the term is also associated with computer technologies, engineering and telecommunication. The adjective 'medical', in its turn, indicates the relationship of the science to researches and practical activities of specialists in the field of MI that are aimed at disease prevention, diagnosis and treatment (Collen, 1986). Therefore, since 1974 till now the term MI has been widely used throughout the world and is present in the titles of such representative MI organizations as International Medical Informatics Association, American Medical Informatics Association or European Federation of Medical Informatics.

In the 1990s, however, the nominative word-combination 'biomedical informatics' (BMI) was more often collaterally used with the term MI in the scientific literature. Such a 
tendency in the terminology shift can have historically-grounded explanations. In particular, the American scientist E. Shortliffe considers that changes in the terminology and ways of its interpretations happened gradually and were induced by modern advanced technologies appearance and their integration into the society life-sustaining activities in the 1990s. They enabled to perform scientific experiments that gave the understanding of human disease nature at molecular and genetic levels (Shortliffe, 2013). Thus, at the end of the 20th century the term 'biomedical informatics' appeared indicating the connection of the specialty not only with medicine but also with biological chemistry, histology, genetics and embryology as the subfields of biomedicine.

The third stage (the present one) is characterized by outlining certain specifics in the terminological system usage within the studied specialty due to information technology penetration into various areas of biomedicine and health care service. It is exactly that period when such terms as 'clinical informatics', 'nursing informatics', 'dental informatics', 'health care informatics', etc. appeared specifying the specialists' professional functioning. Undoubtedly, hierarchy of the given terms within the system of notions concerned with MI is not questioned. On the other hand, the analysis of the terminology operated by the leading world MI organizations enables to conclude about substantial peculiarities of their terminology interpretation.

The distinct hierarchy within the field is noticed in the terminological system developed by the American school, which is represented by American Medical Informatics Association. The American association uses the term 'biomedical informatics' (BMI) in its operation as the basic one for determination of the interdisciplinary specialty that involves biomedicine and informatics (Kulikowski, Shortliffe, Currie, 2012). Hereby, BMI is considered as the applied branch of informatics that develops methodology, technical means and theoretical basis for biomedical information application in order to promote research conduction, health improvement as well as qualitative health care service delivery (AMIA, 2014).

According to the Glossary found on the AMIA's site, trained specialists regard BMI as a general term for the scientific discipline with many other related terms to be the spheres of its practical application. Bioinformatics, in particular, indicates the specialty aimed at studying the usage of technical means of information visualization and presentation in biological systems, especially in molecular biology, genomics and proteomics. The usage of the word-combination 'health informatics' is specific to the applied investigations and practical activities of BMI specialists carried out in the two other subfields - clinical informatics and public health informatics. The goal of the two latter ones consists in ensuring quality of medical service delivery and promoting public health care efficacy (Glossary of Acronyms and Terms Used in Informatics, 2014). In its turn, the terminological unit 'medical informatics' is used in the context of clinical informatics dealing with disease diagnosis and treatment and has been designed for doctors. 'Nursing informatics' and 'dental informatics' should also be mentioned here as clinical informatics branches concerned with the development of information processing systems that are intended to improve work efficiency of the nursing and dentist staff (Kulikowski, Shortliffe, Currie, 2012).

In contrast to the USA experience in the MI terminology usage, the term 'health informatics' (HI) is commonly used in Canada. It is also worth mentioning that Canada's Health Informatics Association (COACH) employs it in wider context if compared to the interpretation of the same term by AMIA. The term determines the specialty which is the convergence of clinical practice, biomedical information management, information 
technologies as well as management practice in medicine and health care system aimed at delivery of quality medical service, disease prevention, popularization of healthy lifestyle, etc. (Health Informatics Professional Core Competences, 2012).

In view of the above said, the HI specialists in Canada should:

- be knowledgeable about the key aspects of the clinical practice that covers the wide range of activities intended for disease diagnosis, prophylaxis and patient treatment;

- possess practical skills in information management that implies biomedical information collection, processing, storage and interpretation;

- be proficient in applying information technologies for the effective information storage or processing;

- acquire competency of management practice that provides a HI specialist with means for medical information system design and monitoring in order to use biomedical information rationally.

It should also be noted that the terms 'health informatics' and 'medical informatics' are practically used in the same contexts which is apparent from both the sites of the Canadian higher educational institutions proposing programs of professional training in $\mathrm{HI}$ and from publications of the Canadian scientists J. Moehr and A. Grant. Besides, some researchers suppose the adjective 'medical' to be connected with disease diagnosis, prevention or treatment, thus forming the field's 'negative' profile. The word 'health' used before 'informatics', to the contrary, shifts the accent and points that the main goal of HI as a specialty is optimal information usage by the field's specialists for improving health of both the individual patient and the population as a whole (Dalrymple, 2011).

The analysis of the terminology formation by European Federation of MI (EFMI) as the formal representative of national MI organizations of the European countries has revealed the preference to 'medical informatics' as the terminological unit for common use. In fact, the term denotes MI both as the science and umbrella term for a number of specialties related to health care and informatics, thus indicating that the terminological system used by EFMI is, to some extent, similar to the above-mentioned AMIA's terminology interpretation.

There is also no coherence in the MI terminology usage by Ukrainian Association for "Computer Medicine", a national member of the international MI organization IMIA. On its official web site, the word-combination 'медична інформатика' is widely used without any definitions proposed for the term. Nevertheless, the association clearly states that its goals are directed at the implementation of new medical information systems, the design of electronic medical history, reformation of health care system in Ukraine as well as the development of biotechnical systems and new software for medical institutions (Ukrainian Association for "Computer Medicine", 2011). Thus, the Ukrainian MI specialists mostly operate the term medical informatics ('медична інформатика' in Ukrainian) as a general one. Moreover, the terminological unit is found in the specialty title "Medical and Biological Informatics and Cybernetics" ("Медична та біологічна інформатика і кібернетика" in Ukrainian) compiled by the Ukrainian MI association for the Ukrainian Higher Attestation Commission as well as in the names of academic disciplines in the curricula of the Ukrainian higher medical educational establishments.

All the above-mentioned MI national organizations are the members of International MI Association (IMIA). It plays a crucial role in information technology implementation into medicine and supports researches aimed at effective informatisation of the health care system as well as development of educational policy in professional training of the MI workforce. IMIA uses the term 'biomedical informatics' in its widest meaning covering all 

(Towards IMIA 2015 - The IMIA Strategic Plan, 2007). Besides, in IMIA recommendations on professional education in MI, the word-combination 'biomedical and health informatics' is used throughout the text (Mantas, Ammenwerth, Demiris, 2010). We consider that such a broad interpretation of the term may indicate that IMIA as the international MI organization makes efforts to unify the field's terminology in order to avoid further misunderstandings and ambiguities. Secondly, simultaneous usage of the terms 'biomedical and health informatics' proves their equivalency, with difference consisting mainly in the term preferences restricted to a specific geographic area.

\section{CONCLUSIONS}

The MI specialty is relatively young and is continuously changing, therefore the unified strategy of using the associated terminology has not been developed yet. It is known that there is a branching system of terms that determine the MI subfields. There are vague boundaries between them and it is not always possible to track where one field finishes and the other one begins. Moreover, the list of adjectives preceding the word 'informatics' is not limited only to such determinants as 'biomedical', 'medical', 'health', 'public health care' or 'clinical'. As the science constantly develops and its further specializations continues, new subspecialties within the existing ones appear, for example imaging informatics, pathology informatics, consumer health informatics etc. (Hersh, 2009). In future, this list may be prolonged with new terms due to advancement of information technologies and the further MI specialization.

In summary, the analysis of the terminological system related to the notion of MI in the context of professional education has enabled to distinguish three terms that are used as equivalents and serve as umbrella terms - 'biomedical informatics', 'medical informatics' and 'health informatics'. They determine the field which specialists are concerned with practical aspects of biomedical information storage, collection, circulation, mining, retrieval, exchange and security, etc. One of the noticed differences among them is the preferences in term usage according to the principle of geographical area. In particular, 'biomedical informatics' is of common usage in the USA, 'health informatics' - in Canada and 'medical informatics' is mostly used in the European countries as well as in Ukraine. Consequently, the term 'medical informatics' has historically become widely used by scientists and teaching staff and serves as generally applicable terminological unit to denote the key theories, concepts and techniques for information technology usage in health care system, biomedicine and hence in the system of professional training of the MI specialists.

The comparative analysis of the MI specialty terminology in the developed Englishspeaking countries is considered an essential ground for further research into the foreign countries' experience in professional training of the MI specialists for the purposes of its progressive ideas implementation into the educational system of Ukraine.

\section{REFERENCES}

1. AMIA: Informatics Professionals. Leading the Way. (2014). Retrieved 17.11.2014 from : http://www.amia.org.

2. Canada's Health Informatics Association. (2012). Health Informatics Professional Core Competences. Toronto: COACH, 22 p. Retrieved 25.07.2014 from: http://www.coachorg.com/en/resourcecentre/resources/Health Informatics Core Competenc ies.pdf. 
3. Collen, M. F. (1986). Origins of Medical Informatics. The Western Journal of Medicine, No 145, p. 778-785.

4. Dalrymple, P. W. (2011). Data, Information, Knowledge: The Emerging Field of Health Informatics. Bulletin of the American Society for Information Science and Technology, Volume 37, Number 5, p. 41-44. Retrieved 12.09.2014 from : Wiley Online Library, DOI:10.1002/bult.2011.1720370512.

5. Glossary of Acronyms and Terms Commonly Used in Informatics. (2014). Retrieved 14.08.2014 from : http://www.amia.org/glossary.

6. Hersh, W. R. (2009). A Stimulus to Define Informatics and Health Information Technology. BMC Medical Informatics and Decision Making, Volume 9, Number 24, 6 p. Retrieved 10.09.2014 from : BioMed Central, DOI:10.1186/1472-6947-9-24.

7. International Medical Informatics Association. (2007). Towards IMIA 2015 - The IMIA Strategic Plan. Brisbane, Australia, 15 p. Retrieved 27.07.2014 from : http://www.imia-medinfo.org/new2/sites/default/files/IMIA_Strategic_Plan_2007final.pdf.

8. Kulikowski, C. A., Shortliffe, E. H. \& Currie, L. M. (2012). AMĪA Board White Paper: Definition of Biomedical Informatics and Specification of Core Competences for Graduate Education in the Discipline. J Am Med Inform Assoc., No 19, p. 931-938. Retrieved 11.10.2014 from : JAMIA, DOI:10.1136/amiajnl-2012-001053.

9. Mantas, J., Ammenwerth, E. \& Demiris, G. (2010). Recommendations of the International Medical Informatics Association (IMIA) on Education in Biomedical and Health Informatics $-1^{\text {st }}$ revision. Methods of Information in Medicine, Volume 49, Number 2, p. 105-120.

10. Shortliffe, E. H. (2013). Biomedical Informatics: Assessing its Evolving Role as both Science and Application. NYU Langone Medical Center: Department of Medicine, 16.04.2013. Retrieved 19.11.2014 from : http://medicine.med.nyu.edu/education/grandrounds/mgr-edward-shortliffe-md-phd-video.

11. Украӥнська асоиіачія "Комп'ютерна медицини» [Ukrainian Association for "Computer Medicine"]. (2014). Retrieved 18.11.2014 from : http://uacm.kharkov.ua/ukr/index.shtml?uabout.htm (in Ukrainian). 